\title{
A dimensão bélica e um possível diálogo com o totalitarismo nazista de alguns hinos oficiais do futebol carioca
}

\author{
A warlike dimension and a possible dialogue with the nazist \\ totalitarism of some official hymns of carioca football
}

\author{
Bruno Castro \\ Universidade Federal do Rio de Janeiro (UFRJ), Rio de Janeiro/Brasil \\ Doutorando em Educação Física \\ profbrunocastro@gmail.com \\ Rafael Valladão \\ Mestre em Educação, UERJ
}

\begin{abstract}
Resumo: Ao analisarmos a letra dos hinos oficiais compostos no período da Primeira República Brasileira, verificamos duas características básicas e predominantes: a primeira característica é a forte influência do pensamento higienista; a segunda é a presença do futebol brasileiro como substituto da atividade bélica. 0 tom marcial que tinham os hinos oficiais não confere a descontração e a originalidade das marchinhas carnavalescas utilizadas por Lamartine Babo nos hinos populares. Foi possível identificar em alguns hinos oficiais características que de alguma forma dialogam com o regime nazista totalitário. 0 tom bélico e racista das letras dos hinos oficiais, em referência ao contexto histórico da época em que foram compostos, expõe a inegável semelhança ideológica com o nazismo, por mais que não tenham tido uma ligação direta.
\end{abstract}

Palavras-Chave: Hinos do futebol; Totalitarismo; Nazismo.

ABSTRACT: After analyzing the letters of the official hymns written in the period of the first Brazilian republic, it is possible to observe two basic and prevailing characteristics: the first characteristic is the strong influence of the hygienist thought; the second is the presence of the Brazilian football as a substitute for war activity. The martial tone that the official hymns had, does not resemble the relaxation and originality of the carnival songs used by Lamartine Babo in the some characteristics in the official hymns that somehow establish a dialogue with the totalitarian nazi regime. When referring to the historical context in which the letters of the official hymns were written, their racist and warlike tone shaws the undeniable ideological resemblance to the Nazism, even thought they haven't had a direct connection.

KEYWORDS: Football hymns; Totalitarianism; Nazism. 


\section{OS HINOS OFICIAIS DO FUTEBOL CARIOCA}

Os denominados hinos oficiais foram provavelmente todos compostos no período da Primeira República Brasileira - entre 1889 e 1930. Este era o período do amadorismo do futebol nacional, que ainda estava em fase de consolidação no país. A seleção brasileira da Copa do Mundo de 1930, a primeira competição internacional como tal, decepcionou muito os torcedores brasileiros, reforçando essa sensação de "amadorismo". No início da Primeira República foi estabelecido um governo provisório, liderado pelo então Marechal Deodoro da Fonseca que estabeleceu algumas mudanças estruturais no país como a reforma do código penal, a separação da igreja e do estado, a naturalização dos estrangeiros residentes no país, a anulação do senado vitalício entre outras. Em 24 de fevereiro de 1891 foi promulgada a primeira constituição da República do Brasil, quando então, estabeleceu-se a Federação dos estados, o sistema presidencial, o casamento civil, a separação dos poderes e a autonomia dos estados e municípios. 0 crescente fortalecimento político e econômico das oligarquias agrárias, que se encontravam insatisfeitas com o modelo ditatorial imposto pelos presidentes militares, leva ao poder o presidente Prudente de Morais gerando o fortalecimento da República Oligárquica, intimamente relacionada aos interesses da aristocracia cafeeira, que representava a elite financeira do Brasil naquele período. Segundo Tubino (2002), foi nesse período que surgiram no país as principais modalidades esportivas. ${ }^{1} 0$ remo, que já vinha sendo praticado desde o Império, desenvolveu-se muito com a fundação dos clubes e tornou-se o principal esporte no país até as primeiras décadas do século XX. Entre o final do século XIX e o início do século XX surgiram a natação competitiva, o basquetebol, o tênis, o futebol, e a esgrima.

Mais adiante, entre os anos 1915 e 1922, período que assistiu a relevantes episódios da história nacional como a promulgação do código civil brasileiro, a epidemia da gripe espanhola, ${ }^{2}$ que enlutou centenas de milhares de famílias, e a deflagração da Primeira Guerra Mundial no governo do presidente Venceslau Brás

\footnotetext{
${ }_{1}^{1}$ SOUZA. Hinos oficiais e hinos populares como representações simbólicas [...], p. 39.

${ }^{2}$ SOUZA. Hinos oficiais e hinos populares como representações simbólicas [...], p. 39.
} 
(1914/1918), surgem os hinos oficiais dos clubes cariocas que, nesse momento, já tinham o futebol como primeiro esporte em preferência popular.

O pioneirismo do Fluminense Football Club (FFC) e do América Football Club (AFC) na composição de hinos em 1915 inaugura um diálogo entre dois dos maiores representantes da identidade nacional na atualidade: a música e o futebol. Unidas essas manifestações refletem com incrível precisão boa parte do nosso imenso universo sociocultural e da nossa "brasilidade". ${ }^{3}$

Ao analisarmos a letra dos hinos oficiais compostos no período da Primeira República Brasileira, verificamos duas características básicas e predominantes que forjaram aspectos semelhantes nas manifestações, permitindo-nos agrupá-las. A primeira característica é a forte influência do pensamento higienista do período nas letras dos hinos. Termos presentes nos hinos como assepsia, limpeza, viril, saúde e nova raça eram muito usados por intelectuais do período que acreditavam que os obstáculos impostos pela base racial brasileira eram insuperáveis. "As medidas para o branqueamento da sociedade brasileira, iniciadas na segunda metade do século XIX, haviam transformado o Centro-Sul em um mosaico de colônias de imigrantes europeus".4 Influenciados por teóricos como Gobineau, Agassiz e Le Bon, os intelectuais brasileiros só viam num programa intenso de imigração uma saída favorável para nação brasileira. Nessa perspectiva, o problema da nacionalidade se radicava no povo que, no limite, deveria ser substituído. ${ }^{5}$ Nesse período também se tentou resolver o problema da saúde pública através da educação, ampliando, assim, a discussão a respeito do papel higienizador da Educação Física tão propalada nos célebres pareceres de Rui Barbosa, que abordavam a necessidade de mais atividades físicas nas escolas e indiretamente valorizavam as práticas esportivas para os brasileiros em geral.

Naquela época, o esporte e a Educação Física eram considerados concomitantemente, não ocorrendo uma distinção teórica. Apesar disso, as

\footnotetext{
${ }^{3}$ SOUZA. Hinos oficiais e hinos populares como representações simbólicas dos principais clubes de futebol do Rio de Janeiro: a contribuição de Lamartine Babo, p. 40.

${ }^{4}$ SOUZA. Hinos oficiais e hinos populares como representações simbólicas dos principais clubes de futebol do Rio de Janeiro: a contribuição de Lamartine Babo, p. 40.

${ }^{5}$ SOUZA. Hinos oficiais e hinos populares como representações simbólicas dos principais clubes de futebol do Rio de Janeiro: a contribuição de Lamartine Babo, p. 40.
} 
competições esportivas já aconteciam isoladamente começando a receber uma interpretação independente das sessões de Educação Física. ${ }^{6}$

A segunda característica que podemos salientar nas letras dos hinos oficiais é a presença do futebol brasileiro como substituto da atividade bélica. Quase todas as composições desse período inicial fazem do time de futebol um batalhão de soldados em marcha para a defesa da honra ou para a busca da "glória", numa espécie de substituição do gramado pelo campo de guerra. Virilidade, altivez, coragem e sacrifício são os principais atributos dos jogadores nas músicas que falam sobre o futebol nesse período, assemelhando-se, em todos os aspectos, aos hinos patrióticos repetidos pelos exércitos desde os rompantes nacionalistas do século XIX.7 Cornelsen denomina os hinos oficiais desse período como "hinos marciais" e destaca ainda a ênfase que eles dão à combatividade ao invés da afetividade. Para o autor, destacam-se ainda os aspectos de virilidade, chegando às raias do belicismo e da predominância de aspectos épicos.

Sem dúvida, hinos como esse, de caráter marcial, carregam consigo marcas - textuais - de um tempo em que o football ainda não tinha se popularizado e se tornado o futebol. E se levarmos em conta o argumento de Cláudia Mattos, de que, nas primeiras décadas de sua existência, o ingresso de negros no clube era interditado, somos levados a deduzir também algumas peculiaridades da sociedade brasileira à época. Mesmo que o seguinte quadro soe demasiado genérico, parecenos que ele não está tão longe da realidade: para se popularizar, o football - ainda na fase do amadorismo - teve de perder o seu "pedigree", teve de deixar de ser um objeto da society elitizada, teve de sair do field para atingir as margens dos centros urbanos brasileiros que cresciam à época, teve de ir para os terrenos baldios, campos improvisados e várzeas modestas. Neste ponto, a década de 1920 é decisiva, pois não só haverá uma maior integração de jogadores negros nas agremiações, com destaque para o Clube de Regatas Vasco da Gama (CRVG), como também começa a se estabelecer a profissionalização dos jogadores de futebol, até ser oficializada em 1933. (grifo nosso). ${ }^{8}$

Abaixo, o quadro que evidenciou as distinções entre os hinos oficiais e populares, num estudo comparativo, que serviu de apoio à pesquisa. Entre os locais visitados para a obtenção de dados históricos, destacaram-se: Museu da Imagem e

\footnotetext{
${ }^{6}$ SOUZA. Hinos oficiais e hinos populares como representações simbólicas [...], p. 40.

${ }^{7}$ SOUZA. Hinos oficiais e hinos populares como representações simbólicas [...], p. 40.

${ }^{8}$ CORNELSEN. Futebol, música e literatura: uma análise dos hinos dos clubes esportivos brasileiros, p. 43.
} 
do Som (MIS), Museu do Futebol (MF), Arquivos do Botafogo de Futebol e Regatas (BFR), além de diversas literaturas adquiridas para a pesquisa, consultadas em diversas bibliotecas, cedidas por familiares ou encontradas nos Clubes.

\begin{tabular}{|c|c|c|c|}
\hline & $\begin{array}{c}\text { Primeiro hino } \\
\text { oficial }\end{array}$ & $\begin{array}{c}\text { Segundo hino } \\
\text { oficial }\end{array}$ & Hino popular \\
\hline FLUMINENSE & $\begin{array}{l}\text { H. Williams (música) } \\
\text { e Coelho Neto (letra) } \\
\text { (1915) }\end{array}$ & $\begin{array}{l}\text { Antônio Cardoso de } \\
\text { Menezes Filho } \\
\text { (1916) }\end{array}$ & $\begin{array}{c}\text { Lamartine } \\
\text { Babo/Lírio } \\
\text { Panicalli } \\
\text { (1949) }\end{array}$ \\
\hline BOTAFOGO & $\begin{array}{c}\text { Hino do Remo } \\
\text { (1921), de } \\
\text { Theophilo de } \\
\text { Magalhães (música) } \\
\text { Alberto Ruiz (letra) }\end{array}$ & $\begin{array}{l}\text { Glorioso. Hymno do } \\
\text { Botafogo F. C. (ano } \\
\text { desconhecido), de } \\
\text { Octacílio Gomes } \\
\text { (letra) e Eduardo } \\
\text { Souto (música) }\end{array}$ & $\begin{array}{c}\text { Lamartine } \\
\text { Babo (1949) }\end{array}$ \\
\hline AMÉRICA & $\begin{array}{l}\text { Hymno à bandeira } \\
\text { (1915), de F. J. } \\
\text { Freire Júnior } \\
\text { (música) e Dr. Luiz } \\
\text { França (letra) }\end{array}$ & $\begin{array}{l}\text { Hymno do America } \\
\text { Foot-Ball-Club } \\
\text { (1922), de F. } \\
\text { Soriano Robert } \\
\text { (música) e } \\
\text { Americano Maia } \\
\text { (letra) }\end{array}$ & $\begin{array}{c}\text { Lamartine } \\
\text { Babo (1947) }\end{array}$ \\
\hline FLAMENGO & $\begin{array}{l}\text { Hymno Rubro-Negro } \\
\text { (1920), de Paulo de } \\
\text { Magalhães }\end{array}$ & Não existe & $\begin{array}{c}\text { Lamartine } \\
\text { Babo (1945) }\end{array}$ \\
\hline VASCO & $\begin{array}{l}\text { Hymno Triunfal do } \\
\text { Vasco da Gama } \\
\text { (1918), de Joaquim } \\
\text { Barros Ferreira da } \\
\text { Silva }\end{array}$ & $\begin{array}{l}\text { Meu Pavilhão (ano } \\
\text { desconhecido), de } \\
\text { Ernani Corrêa e } \\
\text { João de Freitas }\end{array}$ & $\begin{array}{c}\text { Lamartine } \\
\text { Babo - } 1949\end{array}$ \\
\hline
\end{tabular}

Quadro 1: Ano da composição/autor dos hinos oficiais e populares: Conf.: SOUZA, 2009. 
O Hymno Rubro-Negro, dentre os oficiais, pode ser considerado o hino que obteve mais popularidade, entre os torcedores, sendo ainda reconhecido e cantado nos dias atuais. Dos oficiais, este é o hino que mais se aproxima dos hinos populares de Lamartine Babo, por seu caráter mais carnavalesco. Também era chamado de "marchinha", por ter trazido uma linha melódica marcial, porém muito próxima das marchas carnavalescas. A esse respeito, o ex-jogador, ídolo do CRF, Júnior, afirmou, em entrevista para pesquisa, que se lembrava do hino ser cantado nos bailes de carnaval - "talvez até pelo seu ritmo carnavalesco". Segue, abaixo, o “Hymno Rubro-Negro” (1920), de Paulo de Magalhães.

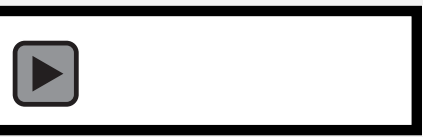

Flamengo, Flamengo

Tua glória é lutar!

Flamengo, Flamengo

Campeão de terra e mar.

Saudemos todos com muito ardor

O pavilhão do nosso amor

Preto e encarnado, idolatrado

Dos mil campeões, do vencedor.

Flamengo, Flamengo

Tua glória é lutar!

Flamengo, Flamengo

Campeão de terra e mar.

Lutemos sempre com valor infindo

Ardentemente, com denodo e fé

Que o seu futuro inda será mais lindo

Que o seu presente que tão lindo é.9

\section{OS HINOS POPULARES DO FUTEBOL CARIOCA}

Os denominados hinos populares dos clubes de futebol do Rio de Janeiro foram lançados no programa "O Trem da alegria”, na Rádio Mayrink Veiga, na década de 1940. Não se sabe ao certo em que circunstâncias eles surgiram, pois os arquivos com os programas gravados sumiram no Golpe Militar de 1964 e, como afirma o

\footnotetext{
${ }^{9}$ Fonte: AQUINO; CRUZ apud SOUZA, p. 25.
} 
jornalista Sérgio Cabral (2008): “[...] a ditadura assassinou a rádio Mayrink Veiga e seus arquivos, mas no Brasil existe outra frente que também aniquila de forma bem parecida, que é a ditadura do descaso", 10 referindo-se à pouca seriedade que, de um modo geral, se tem com o registro da memória nacional. Existem algumas versões para o surgimento e lançamento dos hinos populares: a primeira hipótese menciona que Lamartine Babo, em 1945, lançou 11 hinos de clubes de futebol, na proporção de um por semana. ${ }^{11}$ A segunda hipótese foi levantada pelo músico Luís Filipe Lima, que tocou violão de sete cordas no disco: "Lamartiníadas, a música de Lamartine Babo", gravado no ano de 2004. Lima, que também fez a direção artística do show "Lamartiníadas",12 disse, em entrevista ao jornal Folha de São Paulo, em 22 de fevereiro de 2007, que Babo já havia feito a marcha do Clube de Regatas do Flamengo (CRF) e que foi desafiado pelos colegas de programa a compor as marchas restantes. Essa hipótese se coaduna com as informações do Museu do Futebol, da cidade de São Paulo, SP, que cita 1945 como o ano de composição da marcha rubro-negra, diferente das demais que, segundo o Museu, foram feitas em 1949. Excetuando-se a do América, que não consta data de composição no museu, mas que, segundo Valle (2004), foi composta em 1947.13

A terceira hipótese dada, também pelo músico, envolve um possível patrocinador que teria incentivado Babo. Existe, ainda, uma quarta hipótese levantada pelo radialista Abi Rian (2008), que fala sobre uma possível passagem, em que Lamartine teria sido trancado por amigos em um apartamento e só liberado quando entregasse os hinos prontos. ${ }^{14}$ A opção usada no Quadro 1, que trata do ano da composição/autor dos hinos oficiais e populares, utilizou como referência as datas obtidas no Museu de Futebol de São Paulo, no caso de FFC, BFR, CRF e CRVG, por se tratar da pesquisa mais contemporânea sobre o tema. No caso do AFC, que não tem registro de data de composição no Museu do Futebol foi

\footnotetext{
${ }^{10}$ SOUZA. Hinos oficiais e hinos populares como representações simbólicas [...], p. 100.

${ }^{11}$ SOUZA. Hinos oficiais e hinos populares como representações simbólicas [...], p. 100.

${ }^{12}$ SOUZA. Hinos oficiais e hinos populares como representações simbólicas [...], p. 100.

${ }^{13}$ SOUZA. Hinos oficiais e hinos populares como representações simbólicas [...], p. 101.

${ }^{14}$ SOUZA. Hinos oficiais e hinos populares como representações simbólicas [...], p. 101.
} 
utilizado o data presente no livro "América - Antologia Lírica de um sentimento obstinado" de autoria de Fernando Bastos do Valle (2004). ${ }^{15}$

A supervisora de direitos autorais, Marli dos Santos (2009), da Companhia Industrial de Discos (CID), que trabalha na empresa, há pelo menos vinte anos, relatou que em dezembro de 1977 foi produzido um disco contendo as marchas populares de diversos clubes brasileiros, dentre elas as marchas de FFC, BFR, AFC, CRF e CRVG. ${ }^{16}$ Segundo Santos (2009), o registro dos hinos, que foi gravado pela "Banda Galera Campeã", é, até hoje, um dos recordistas de venda da gravadora e tem ampla execução em rádios, festas e comemorações, o que é mais um dado que comprova a vitalidade e atemporalidade das obras de Babo. ${ }^{17}$ Santos também indicou para pesquisa os contatos da Editora "Fermata do Brasil", em São Paulo, administradora dos direitos autorais dos hinos populares de Babo, onde se obteve a informação de que os hinos foram editados no ano de $1953 .{ }^{18} \mathrm{~A}$ funcionária ainda enviou os dados da ficha técnica do Long Play número 4027, intitulado Hino dos Campeões vol. 1, lançado em dezembro de 1977.19

O jornalista Chico Pinheiro (2008) ressalta o tom marcial que tinham os hinos oficiais, o que, em sua opinião, não confere àquelas obras a descontração e a originalidade das marchinhas carnavalescas utilizadas por Babo nos hinos populares. ${ }^{20}$ Essa descontração apontada por Pinheiro começou a ser esboçada, na opinião deste autor, por Theophilo de Magalhães e Alberto Ruiz, na composição do hino oficial do Club de Regatas Botafogo (CRB), ${ }^{21}$ que foi a única

\footnotetext{
${ }^{15}$ SOUZA. Hinos oficiais e hinos populares como representações simbólicas [...], p. 101.

${ }^{16}$ SOUZA. Hinos oficiais e hinos populares como representações simbólicas [...], p. 101.

${ }^{17}$ SOUZA. Hinos oficiais e hinos populares como representações simbólicas [...], p. 101.

${ }_{11}^{18}$ SOUZA. Hinos oficiais e hinos populares como representações simbólicas [...], p. 101.

${ }^{19}$ SOUZA. Hinos oficiais e hinos populares como representações simbólicas [...], p. 101.

${ }^{20}$ SOUZA. Hinos oficiais e hinos populares como representações simbólicas [...], p. 41.

${ }^{21}$ A gênese do BFR deu-se a 8 de dezembro de 1942, quando, então, o destino convergira para mesma quadra de basquete como adversárias, as equipes do Club de Regatas Botafogo (CRB) e do Botafogo Football Club (BFC), carinhosamente apelidados pelos torcedores por: "A Estrela Solitária" e "O Glorioso" respectivamente. Na ocasião disputava-se o campeonato carioca. O atleta Armando Albano, do (BFC), morre fulminado por uma síncope e o jogo é imediatamente suspenso e não mais disputado. A tragédia irmanou as duas equipes tornando a fusão um processo inexorável (PEPE et al, 1996 apud SOUZA, 2009). Os clubes que nasceram no bairro de Botafogo, no município do Rio de Janeiro, possuíam as mesmas cores e eram frequentados muitas vezes pelas mesmas famílias alvinegras, que acabaram sendo 0 amálgama que permitiu a ligação entre os dois Botafogos. Esse oportuno casamento entre "A Estrela Solitária" e "O Glorioso" acarretou a fusão de patrimônios, equipes, histórias, glórias e simbolismos (SOUZA, 2009, p. 53-54).
} 
obra do período a sugerir, explicitamente na capa da partitura, a execução em ritmo de Polka-marcha ou Rag-time e imprimir uma modalidade de poesia desprovida de conteúdo bélico e higienista, distanciando-se progressivamente da formalidade da maioria das obras oficiais.

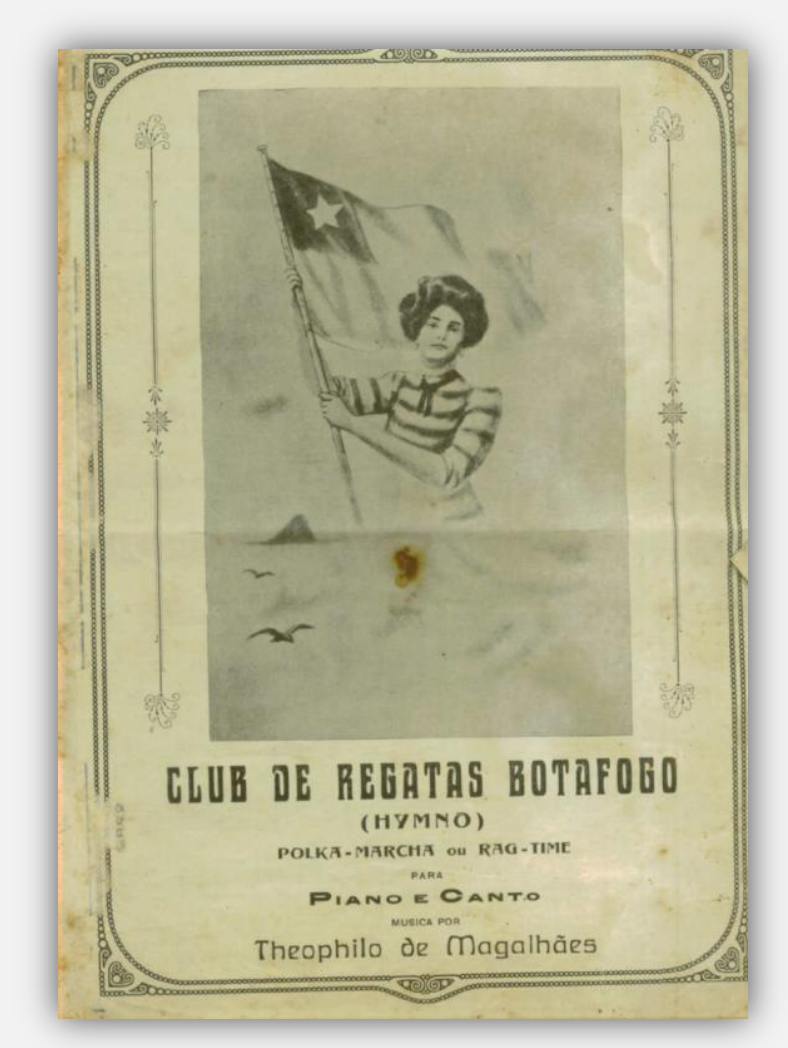

Fig. 1: capa da partitura do hino oficial do (CRB).

Concordando com esta pesquisa e com Chico Pinheiro, Elcio Cornelsen também destaca em seu estudo sobre os hinos de futebol de Portugal e do Brasil essa transição ocorrida entre os hinos oficiais e populares brasileiros, que vão na contramão de ideias de eugenia racial, ou mesmo do tom belicista, tendo Lamartine Babo a sensibilidade de compor músicas com alegria e tolerância.

Nosso estudo revelou também que pode haver distinções de ordem cultural, pois os clubes portugueses, em especial o Benfica, não passaram por um fenômeno que emprestasse um caráter popular a seus hinos, como é o caso dos clubes brasileiros, num processo em que Lamartine Babo não só foi pioneiro, como também fez escola e 
influenciou a criação de novos hinos para clubes de todas as partes do país, tendo por fonte de inspiração as marchinhas de Carnaval. ${ }^{22}$

Cornelsen acredita que o surgimento dos hinos populares acompanha a profissionalização e popularização do futebol, posteriores às décadas de 1910 e 1920. ${ }^{23}$ E destaca novamente a importância dos hinos dos clubes do Rio de Janeiro, assim como as composições de Lamartine Babo.

\section{UM POSSÍVEL DIÁLOGO COM O TOTALITARISMO NAZISTA}

O conceito de totalitarismo, de acordo com Cornelsen, foi utilizado pela primeira vez na Itália, por Giovanne Amendola (1882-1926), com o objetivo de expor o fascismo italiano que atentava contra a democracia no período. 24

O conceito de totalitarismo ou regimes totalitários podem ser definidos como: "sistemas de governo que tentariam conformar os cidadãos dentro de uma ideologia, para isso fazendo uso de mecanismos de controle e coação, e, ao mesmo tempo, buscariam mobilizá-los".25 Segundo Cornelsen, Friedrich e Brzezinski (1996) definiram seis características comuns a todos os regimes totalitários:

1) uma ideologia elaborada, composta de uma doutrina oficial que abrange todos os aspectos vitais da existência humana, e diante da qual todos os que vivem nessa sociedade têm de, pelo menos, se manter passivos; tal ideologia é direcionada e projetada para um estado final ideal da Humanidade, exigência fundamentada na rejeição radical da sociedade vigente e na conquista do mundo para uma nova sociedade; 2) um único partido de massa, no caso típico, conduzido por um único ditador e formado por uma percentagem relativamente baixa da população total (até $10 \%$ ) de homens e mulheres, no qual uma base rígida está atrelada à ideologia apaixonadamente e sem restrição e preparada para incentivar, de todas as formas, a imposição de sua aceitação. Um partido dessa natureza é organizado hierárquica e oligarquicamente e, de modo característico, superposto à burocracia do Estado ou totalmente atrelado a ela; 3) um sistema de terror, sobre base física ou psíquica, posto em prática por meio de controle através do partido e da polícia secreta, mas que também vigia o partido e, de modo característico, não está direcionada exclusivamente contra "inimigos" declarados do regime, mas também contra segmentos da população

\footnotetext{
${ }^{22}$ CORNELSEN. Hinos de Futebol em Portugal e no Brasil: dos hinos marciais aos populares, p. 13. CORNELSEN. Futebol, música e literatura: uma análise dos hinos dos clubes esportivos brasileiros, p. 3. ${ }^{24}$ CORNELSEN. Totalitarismo, p. 2.

${ }^{25}$ CORNELSEN. Totalitarismo, p. 2.
} 
mais ou menos escolhidos arbitrariamente. 0 terror, seja ele emanado da polícia secreta ou da pressão exercida pelo partido sobre a sociedade, faz uso sistemático da ciência moderna, sobretudo da psicologia científica; 4) um completo monopólio, condicionado tecnologicamente, do controle de todos os meios efetivos de comunicação de massa, como a imprensa, o rádio e o cinema, nas mãos do partido e do Estado; 5) um completo monopólio, condicionado tecnologicamente, do emprego efetivo de todos os armamentos pesados; 6) uma vigilância e condução central de toda a economia através da coordenação burocrática de corporações legais anteriormente independentes, de modo característico, sob influência de outras sociedades e empresas. ${ }^{26}$

No entanto, Cornelsen também descreve diferenças entre totalitarismo e autoritarismo:

Tomando por base algumas considerações propostas por Eckhard Jesse, podemos apontar os seguintes aspectos: (a) Um sistema totalitário se diferencia por uma centralização rígida de poder, enquanto um sistema autoritário ainda assegura certo pluralismo, mesmo que limitado; (b) um sistema totalitário tem por base uma ideologia exclusiva, enquanto um sistema autoritário se fundamenta numa postura tradicional nãoconformada rigidamente; (c) enquanto um sistema totalitário força a mobilização das massas através de mecanismos de integração e de persuasão, um sistema autoritário renuncia a uma participação dirigida das massas, satisfazendo-se com a apatia política geral. ${ }^{27}$

O século XX para autor foi o século da superação do totalitarismo na Europa que teve o seu ápice com o nazismo alemão de Adolf Hitler e o já citado fascismo italiano de Benito Mussolini. Em 1939 já era corrente aplicar o termo aos dois regimes (nazista e stalinista) que eram as principais forças contra os aliados na $2^{\underline{a}}$ Guerra Mundial. A partir da deflagração da guerra com a invasão da Polônia, em 1o de setembro de 1939, e o ataque por parte da Alemanha à União Soviética, em 22 de junho de 1941, todas as atenções e estudos sobre o totalitarismo se voltaram para o nazismo de Hitler.

Os Jogos Olímpicos de 1936 foram uma das tentativas de legitimação do totalitarismo do regime nazista, perante a opinião pública internacional, e de criar uma nova imagem da Alemanha. Para a realização das olimpíadas, órgãos como a Gestapo e $S A$, procuraram ocultar do Comitê Olímpico Internacional (COI) e dos

\footnotetext{
${ }^{26}$ CORNELSEN. Totalitarismo, p. 4-5.

${ }^{27}$ CORNELSEN. Totalitarismo, p. 3.
} 
visitantes estrangeiros a real situação política do país, como a perseguição contra judeus, repressão política e cultural. No entanto, tais ações como a política antissemita despertaram a desconfiança do COI, que pensou em mudar a sede dos Jogos Olímpicos. No entanto, as olimpíadas foram realizadas, uma vez que os nazistas conseguiram convencer o mundo de que não haveria propaganda ideológica do regime e que os atletas e a população judaica participariam também. A imprensa foi o principal veículo para este projeto de poder e manipulação nazista. Havia as denominadas "instruções de imprensa" (Presseanweisungen), que eram expedidas em conferências diárias pelo Estado Nazista, que contavam com a participação obrigatória de um redator de cada jornal ou revista. O Setor IV do Ministério da Propaganda, na figura do ministro Joseph Goebbels (1897-1945), era responsável por essas instruções, que serviam basicamente para obrigar os meios de comunicação a veicularem notícias falsas de qualquer natureza que lhe fossem impostas ou, simplesmente, para proibir a veiculação de determinadas notícias. Durante o ano dos Jogos Olímpicos de 1936, na Alemanha, foram expedidas em média dez instruções por dia. ${ }^{28}$

Apesar de não haver encontrado nenhuma ligação direta dos hinos oficiais do futebol carioca com o discurso totalitário nazista, foi possível identificar, em alguns desses hinos, características que, de alguma forma, dialogam com o regime de Hitler. $\mathrm{O}$ primeiro hino oficial do FFC foi executado em público pela primeira vez em 29 de julho de 1915, em um baile realizado no ringue de patinação, quando, então, aconteciam os festejos comemorativos pela construção da nova sede do clube. A obra foi composta por Coelho Neto, sobre música de H. Williams, It's a long, long way to tipperary, muito cantada e executada no Rio de Janeiro, durante a Primeira Guerra Mundial, 1914 a 1918, pelos marinheiros dos navios de guerra ingleses, que ancoravam na Guanabara. ${ }^{29}$ Este hino, "Primeiro Hino Oficial do Fluminense Football Club" (1915), de H. Williams e Coelho Neto, possuem alguns detalhes em sua letra que destacamos a seguir:

\footnotetext{
${ }^{28}$ CORNELSEN. Esporte e discurso totalitário: os Jogos Olímpicos de Berlim e o discurso nazista na imprensa, p. 323.

${ }^{29}$ SOUZA. Hinos oficiais e hinos populares como representações simbólicas [...], p. 23.
} 
O Fluminense é um crisol Onde apuramos a energia Ao pleno ar, ao claro sol Lutando em justas de alegria O nosso esforço se congraça Em torno do ideal viril De avigorar a nova raça Do nosso Brasil!

Corrige o corpo como artista Vida imprime à estátua augusta Faz da argila uma robusta Peça de aço onde a alma assista. $\mathrm{Na}$ arena como na vida Do forte é sempre a vitória. Do estádio foi que a Grécia acometida Irrompeu para a glória!

II

Ninguém no clube se pertence; A glória aqui não é pessoal: Quem vence em campo é o Fluminense Que é, como a Pátria, um ser ideal. Assim nas justas se congraça Em torno dum ideal viril A gente moça, a nova raça Do nosso Brasil!

Adestra a força e doma o impulso, Triunfa, mas sem alardo, o herói é bravo mas galhardo Tão forte d'alma que de pulso. A força esplende em saúde E abre o peito à bondade.

A força é a expressão viva da virtude E garbo da mocidade! 30

${ }^{30}$ Fonte: COELHO NETO apud SOUZA, p. 38 
"Adestra", "corrige o corpo", "pátria, um ser ideal”, "o herói é bravo", “dum ideal viril" são palavras que, se analisadas fora de um contexto, já poderiam nos remeter a algum tipo de influência ou expressão do período nazista. 0 que também seria ratificado com o verso "De avigorar a nova raça". Mas, analisando o primeiro hino dentro de todo o seu contexto, observa-se que a dimensão melódica é uma marcha marcial de inspiração bélica, muito comum a outros hinos do período. A primeira gravação encontrada pela pesquisa foi uma versão "caribenha dançante" contemporânea, lançada em 2000, pelo intérprete e produtor artístico Heitor D’Alincourt. 0 segundo registro é uma versão de baixa qualidade sonora, feito por uma banda marcial desconhecida, parecendo ser um registro bem antigo. 0 terceiro registro parece ser mais contemporâneo, pelo fato de ter uma boa qualidade sonora. Foi feito pela banda marcial do corpo de fuzileiros navais, em uma primorosa execução. 0 último registro de áudio encontrado é instrumental, executado por piano e flauta. A letra é um retrato fiel do perfil elitista e higienista do clube, que atinge o ápice dessa atmosfera, quando sugere que as vitórias são disputadas "pelos mais fortes, mais destros e sagazes", dando uma nítida conotação de raça superior que, de maneira excludente, afastava do convívio "os fracos", na esfera biológica e social. ${ }^{31}$

Este tipo de pensamento se coadunava com o ideal nazista de "beleza e combatividade", de exaltação do mito ariano de raça superior e o culto ao corpo do soldado a ser preparado para a guerra. De acordo com Cornelsen, este ideal era propagado pela imprensa e pelo cinema como, por exemplo, a cineasta Leni Riefenstahl, que recebeu uma verba de 1,5 milhão de marcos para gravar o filme Olympia.

[...] a cineasta recebeu do Governo nazista, no outono de 1935, para rodar um filme que pudesse "documentar" os Jogos Olímpicos de Berlim segundo a ideologia apregoada pelo Estado, em que a exaltação do mito ariano e o culto ao corpo como expressão de força de combate eram algumas de suas colunas de sustentação. ${ }^{32}$

\footnotetext{
${ }^{31}$ SOUZA. Hinos oficiais e hinos populares como representações simbólicas [...], p. 50.

${ }^{32}$ CORNELSEN. Esporte e discurso totalitário: os Jogos Olímpicos de Berlim e o discurso nazista na imprensa, p. 317.
} 
Outro fator interessante foi a aquisição por parte dos nazistas de seus antigos proprietários em Roma, da escultura de Myron, o Discóbolo, símbolo atual da Educação Física brasileira. Estes acreditavam que a obra era a "expressão fiel do ideal humano de beleza e combatividade". ${ }^{33}$ Diversos outros hinos oficiais, que incluo ao final como anexo, possuem todo esse contexto de vencer a batalha, a guerra e de eugenia racial, como o "Glorioso Hymno do Botafogo Football Club", com expressões como "a lutar com afan" "corrigindo a juventude" "Seja a pátria da força e da saúde". O segundo hino oficial do FFC: "Nossas bolas são nossa metralha", "Um bom goal, nosso tiro de morte". Ou mesmo o primeiro do América: “Tem em cada um de nós um soldado", "Se preciso a marchar para a morte”.

Por mais que considere improvável uma influência direta de algum órgão nazista como a Gestapo, SS, SA ou até mesmo do próprio Hitler sobre os autores dos hinos oficiais dos clubes de futebol carioca, devendo-se mais o tom bélico e racista das letras ao contexto histórico da época em que foram compostos, é inegável a semelhança ideológica. Neste sentido, se faz necessária uma pesquisa mais aprofundada que mergulhe fundo nas biografias desses autores, suas influências, posições políticas, assim como uma possível intervenção nazista no Brasil, haja vista o alcance da manipulação da opinião pública internacional em torno dos Jogos Olímpicos na Alemanha nazista em 1936.

\section{REFERÊNCIAS}

CORNELSEN, Elcio. Esporte e discurso totalitário: os Jogos Olímpicos de Berlim e o discurso nazista na imprensa. In: MARI, Hugo; MACHADO, Ida Lucia; MELLO, Renato de (org.). Análise do Discurso em perspectivas. Belo Horizonte: FALE/UFMG, 2002, p. 315-350.

CORNELSEN, Elcio Loureiro. Futebol, música e literatura: uma análise dos hinos dos clubes esportivos brasileiros. Ciência e Cultura, v. 66, n. 2. São Paulo, junho, 2014a.

CORNELSEN, Elcio Loureiro. Hinos de Futebol em Portugal e no Brasil: dos hinos marciais aos populares. Esporte e Sociedade, v. 9, n. 23, março, 2014b.

\footnotetext{
${ }^{33}$ CORNELSEN. Esporte e discurso totalitário, p. 318.
} 
CORNELSEN, Elcio Loureiro. Totalitarismo. Revista Eletrônica Literatura e Autoritarismo, v. 1, n. 14, março, 2009.

SOUZA, Bruno de Castro. Hinos oficiais e hinos populares como representações simbólicas dos principais clubes de futebol do Rio de Janeiro: a contribuição de Lamartine Babo. 2009. 211 f. Dissertação (Mestrado) - Curso de Ciência da Motricidade Humana, Universidade Castelo Branco, Rio de Janeiro, 2009.

Hinos oficiaIs (Gravações de Bruno Castro)

Hino oficial do Flamengo: https://bit.ly/2HZY59H.

1ํhino oficial do América: https://bit.ly/2jz3lki.

$1^{\circ}$ hino oficial do Botafogo: https://bit.ly/2KEKUfL.

$1^{\circ}$ hino oficial do Fluminense: https://bit.ly/2JZ2aLU.

1ำ hino oficial do Vasco da Gama: https://bit.ly/2JUuoXW.

$2^{\circ}$ hino oficial do América: https://bit.ly/2KH3qV4.

2ำ hino oficial do Botafogo: https://bit.ly/2jCiVRX.

$2^{\circ}$ hino oficial do Fluminense: https://bit.ly/2jxrY6z.

$2^{\circ}$ hino oficial do Vasco da Gama: https://bit.ly/2rpoRlp.

Hinos POPULARES (Gravações de Bruno Castro)

Hino popular do América: https://bit.ly/2HZ1uFs.

Hino popular do Botafogo: https://bit.ly/2FNbjo7.

Hino popular do Flamengo: https://bit.ly/2jB7JVj.

Hino popular do Fluminense: https://bit.ly/2wgTONB.

Hino popular do Vasco da Gama: https://bit.ly/2HR5D2p. 


\section{ANEXO}

Outros hinos oficiais dos clubes cariocas com marchas marciais, de inspiração bélica, que podem dialogar com o totalitarismo nazista:

Hino à bandeira do América $(1915)^{34}$

Francisco José Freire Júnior e Luiz França

Pavilhão alvi-rubro tremulai!...

Aquecei-vos ao sol de mais victorias!...

Entre os louros colhidos nas pelejas,

Recobrai mais alento para as glórias.

Descobri vossa fronte magestosa,

Recebi a coroa consagrada.

Ao calor que vos fez heróica e forte,

Sacrosanta bandeira abençoada!

(Estribilho)

Companheiros, avante! Caminhemos, Junto à sombra sagrada destas cores, Que o pendão bicolor em si resumem, Num baptismo de glorias e de flores.

II

Agitai vosso porte as brandas auras, Que vos beijam os pés em doce enleio, Que repetem além os mil triumphos,

Esta uncção que vos traz mais vida ao seio.

Vosso nome queremos, sempre altivo, Relembrando um passado sobranceiro, Que o presente venéra nos mostrando, Um futuro de luz mais altaneiro.

${ }^{34}$ CUNHA; CASTRO apud SOUZA, p. 123. 
Segundo Hino Oficial do Fluminense Football Club (1916)

Antônio Cardoso de Menezes Filho

Companheiros de luta e de glória

Na peleja incruenta e de paz

Disputamos no campo a vitória

Do mais forte, mais destro e sagaz!

Nossas liças de atletas são mansas

Como as querem os tempos de agora

Ressuscitam heróicas lembranças

Dos olímpicos jogos de outrora

Não nos cega o furor da batalha

Nem nos fere o rival, se é mais forte!

Nossas bolas são nossa metralha

Um bom goal, nosso tiro de morte

Fluminense, avante, ao combate

Nosso nome cerquemos de glória

Já se ouve tocar a rebate

Disputemos no campo a vitória.

${ }^{35}$ Museu da Imagem e do Som apud SOUZA. 
Hymno Triunfal do Vasco (1918)

Joaquim Barros Ferreira da Silva

Clangoroso apregoa, altaneiro O clarim estridente da fama Que dos clubes do Rio de Janeiro O invencível é o Vasco da Gama

Se vitórias já tem no passado Glórias mil há de ter no porvir O seu nome é por nós adorado Como estrela no céu a fulgir!

(Refrão)

Avante então Que pra vencer Sem discussão Basta querer Lutar, lutar Os vascaínos De terra e mar Os paladinos.

É mundial A sua fama Vasco da Gama Não tem rival Mais uma glória Vai conquistar Lutar, lutar

Para a vitória.
Sobre os peitos leais, vascaínos Brilha a Cruz gloriosa de Malta Corações varonis, leoninos Que o amor pelo Vasco inda exalta.

Quando o Vasco em qualquer desafio Lança em campo o seu grito de guerra Invencível, nervoso arrepio Faz tremer o rival e a terra!

(Refrão)

Vascaínos, avante é lutar Sempre o Vasco venceu quando quis

Quer em terra, ou ainda no mar Nunca o Vasco baixou a cerviz

Viva, pois, nosso Vasco da Gama Nosso clube leal, valoroso. Tudo o diz, assegura e proclama Nosso Vasco é o mais glorioso.

${ }^{36} \mathrm{ROCHA}$ apud SOUZA, p. 245-246. 
Hymno do America Foot-Ball-Club (1922) ${ }^{37}$

F. Soriano Robert e Americano Maia

Alvi Rubro pendão da victória Que nos campos de lucta se agita Ao bafejo bemdicto da glória Que a luctar e a vencer nos incita

Alvi Rubro pendão defraudado Sobre a moça energia do forte Tem em cada um de nós um soldado Se preciso a marchar para a morte

O América sempre na frente A victória é ha muito seu hall Vigoroso, tenaz e valente "Passe", "dimbla", "schot", "goall"

Alvi Rubro pendão posto ao vento Farfalhado, soberbo as tuas cores Nos sentimos brotar nosso alento Novas forças e novos vigores

Nos sentimos ao ver-te, estandarte Transformarem-se espinhos em flores Simbolisas, o augusto baluarte Do campeão, do campeão dos vencedores.

${ }^{37}$ BRANCO apud SOUZA, 2009. 
Hymno do Botafogo Football Club (ano desconhecido) ${ }^{38}$ Eduardo Souto e Octacílio Gomes

\section{Botafogo Gentil!}

Pura Glória do esporte brasileiro

A expressão mais viril

Da energia e do brio verdadeiro!

A lutar com afan,

Tu farás, corrigindo a juventude,

Que o Brasil de amanhã

Seja a pátria da força e da saúde

Teu futuro e teu passado,

Defendidos sem repouso,

Façam sempre respeitado

Esse teu nome glorioso!

O alvinegro pendão,

O caminho a apontar-nos da victória,

Do Cruzeiro o clarão,

Ás estrellas traduza a nossa glória!

Não te falte jamais

Da ousadia a nobreza e o puro fogo

Que o primeiro, entre os mais,

Ha de ser, ó glorioso Botafogo!

Recebido para publicação em 20 dez. 2017.

Aprovado em 03 maio 2018.

${ }^{38}$ Arquivo do Botafogo de Futebol e Regatas apud SOUZA, 2009. 